\title{
Propionate induced effects on feed intake and blood parameters in sheep
}

\author{
HGD Leuvenink, EJB Bleumer, P Kruys, LJGM Bongers \\ Department of Human and Animal Physiology, Wageningen Institute of Animal Sciences, Agricultural University, \\ Haarweg 10, 6709 PJ, Wageningen, The Netherlands
}

\begin{abstract}
All animals eat discrete meals which approximately balance the animals requirement for nutrients. Size and frequency of meals may be regulated in order to vary the amount ingested. If feed quality is sufficiently high, meal size is not limited by the capacity of the stomachs or the intestines. Therefore several humoral factors have been ascribed a role in the short-term regulation of feed intake.
\end{abstract}

The liver, due to its strategic position in the bloodstream and its extensive neural innervation, is thought to be one of the potential sites for controlling substances. Infusion of substrate into the portal vein is more potent than infusion into other (peripheral) veins.

Six swifter crossbred (Texel male $x$ Flemish female) mature wether sheep, kept in ground pens were provided with catheters in the portal vein (PV), the mesenteric vein (MV), and the jugular vein (JV). The animals were fed grass pellet diets $(-22.7 \% \mathrm{CP})$. Feed was offered for 90 -min periods $\left(45 \mathrm{~g} / \mathrm{kg}^{0.75}\right)$, three times daily. Starting at the $08.00 \mathrm{~h}$ feeding time, $\mathrm{Na}$ propionate was infused for $20 \mathrm{~min}$ at 0,1 or 2 $\mathrm{mmol} / \mathrm{min}$ into the $\mathrm{MV}$ and in another series of experiments at 0 or $2 \mathrm{mmol} / \mathrm{min}$ into the $\mathrm{PV}$. Blood was sampled from the JV and PV 10 minutes before and 10 minutes after start of the infusion, and 10 minutes after ending the infusion. Samples were analysed for volatile fatty acids, glucose and insulin.

Infusion of propionate into the MV decreased feed intake by $30 \%(P<0.025)$. In Table, the effects of propionate infusions into the MV on propionate $(\mathrm{mmol} / \mathrm{l})$ and insulin levels $(\mu \mathrm{lU} / \mathrm{ml})$ are summarized.

Infusion into the PV did not result in a decreased feed intake despite similar increases in propionate and insulin as when propionate was infused into the MV. The different effects on feed intake according to site of infusion may possibly be attributed to differences in distribution of propionate to the liver, and/or the presence of propionate receptors in the mesenteric/portal vein region.

\begin{tabular}{|c|c|c|c|c|}
\hline & & $1 \mathrm{~m}$ & $\operatorname{nin}$ & \\
\hline & & & & \\
\hline & prop & ins & prop & ins \\
\hline before & 0.04 & 62 & 0.31 & 61 \\
\hline during & 0.09 & $138^{*}$ & 1.31 & 142 \\
\hline after & 0.05 & 71 & 0.39 & 72 \\
\hline
\end{tabular}

\begin{tabular}{|c|c|c|c|}
\hline \multicolumn{4}{|c|}{$2 \mathrm{mmol} / \mathrm{min}$} \\
\hline \multicolumn{2}{|c|}{ JV } & \multicolumn{2}{|c|}{ PV } \\
\hline prop & ins & prop & ins \\
\hline 0.05 & 67 & 0.35 & 68 \\
\hline $0.24^{*}$ & $245^{\star}$ & $1.78^{*}$ & $297^{\star}$ \\
\hline 0.07 & 86 & 0.47 & 76 \\
\hline
\end{tabular}

